\title{
Analisis Faktor-Faktor Yang Mempengaruhi Pendapatan Pedagang Kaki Lima (Studi Kasus Wisata Taman Jomblo Kotabaru Jambi Pasca Pandemi Covid-19)
}

\author{
Ratih Rosita $^{1}$, Irmanelly ${ }^{2}$, Ermaini $^{3}$ \\ Fakultas Ekonomi Dan Bisnis Universitas Muhammadiyah Jambi \\ Correspondence email: ratihrosita11@gmail.com; 73irmanelly@gmail.com; ermaini73@gmail.com
}

\begin{abstract}
Abstrak_ Tujuan dari penelitian ini yaitu menjelaskan Faktor-Faktor yang mempengaruhi pendapatan pedagang kaki lima (Studi Kasus Wisata Taman Jomblo Kotabaru Jambi Pasca Pandemi Covid-19) secara simultan dan parsial. Metode penelitian ini merupakan penelitian deskriptif dengan metode kuantitatif dengan menggunakan alat analisis regresi linier berganda. Sampel penelitian sebanyak 58 dari total populasi 136 pedagang. Pengumpulan data dilakukan dengan menggunakan kuesioner. Hasil penelitian berdasarkan hasil regresi linier berganda terbukti bahwa secara simultan dan parsial variabel packaging, modal dan waktu dagang berpengaruh signifikan terhadap pendapatan pedagang kaki lima (Studi Kasus Wisata Taman Jomblo Kotabaru Jambi Pasca Pandemi Covid-19). Berdasarkan hasil penelitian rekomendasi yang diharapkan dapat menjadi masukan Hendaknya pihak pemerintah Kota Jambi dapat lebih memperhatikan lagi faktor-faktor tersebut untuk meningkatkan pendapatan para pedagang kaki lima guna untuk meningkatkan kesejahteraan masyarakat di masa covid-19 seperti ini yang banyak terjadi PHK besar besaran. Jumlah unit usaha yang memiliki pengaruh yang paling besar terhadap jumlah tenaga kerja, semakin banyak jumlah UKM yang berdiri, maka akan semakin banyak menciptakan lapangan pekerjaan, sehingga penyerapan tenaga kerja juga akan meningkat dan tingkat penggangguran dapat ditekan.
\end{abstract}

Kata Kunci: Pendapatan, Packaging, Modal dan Waktu Dagang.

Abstract_ The purpose of this study is to explain the factors that influence the income of street vendors (Case Study of Taman Jomblo, Kotabaru Jambi Tourism after the Covid-19 Pandemic) simultaneously and partially. This research method is a descriptive study with quantitative methods using multiple linear regression analysis tools. The research sample was 58 from a total population of 136 traders. Data collection was carried out using a questionnaire. The results of the study are based on the results of multiple linear regression, it is proven that simultaneously and partially the variables of packaging, capital and trading time have a significant effect on the income of street vendors (Case Study of Taman Jomblo Kotabaru Jambi Post-Covid-19 Pandemic). Based on the results of research recommendations that are expected to be input. The Jambi City government should pay more attention to these factors to increase the income of street vendors in order to improve the welfare of the community during the Covid-19 period like this, where there were many large layoffs. The number of business units that have the greatest influence on the number of workers, the more the number of small and medium enterprises that are established, the more jobs will be created, so that labor absorption will also increase and the unemployment rate can be suppressed.

Keywords: Income, Packaging, Capital and Trading Time.

\section{PENDAHULUAN}

Kota Jambi adalah salah satu kota di Indonesia yang sedang berkembang. Biasanya suatu kota yang sedang berkembang melakukan pembangunan ekonomi dengan sangat pesat serta melakukan berbagai perkembangan pada sektor seperti sektor ekonomi, politik, sektor social budaya dan lain sebagainya. Dengan adanya pembangunan pada kota dimaksudkan untuk memajukan kota tesebut, terutama pada sektor ekonomi yakni bertujuan untuk mengembangkan perekonomian dikota tersebut sehingga meningkatkan taraf hidup masyarakatnya.

Sebagai kota yang sedang berkembang, Kota Jambi banyak melakukan pembangunan infrastruktur dan fasilitas - fasilitas umum seperti perkantoran, taman reskreasi, ruang publik, mall, dan lainnya. Tetapi pembangunan tersebut tidak selalu memberikan kehidupan ekonomi masyarakat yang lebih baik. Meski terdapat banyak perkantoran dan kegiatan pusat industri yang berkembang, namun masih banyak masyarakat Kota Jambi yang tidak bekerja dan ditambah dengan jumlah pendatang yg datang untuk mencari mata pencaharian. Hal ini membuktikan masih ada ketidakmampuan penyerapan tenaga kerja di Kota Jambi meskipun banyaknya perkembangan ekonomi yang sedang berkembang.

Pedagang kaki lima makanan dan minuman di trotoar sekitar Taman Jomblo Kecamatan Kota Baru Jambi adalah salah satu jenis pedagang kaki lima (PKL) yang ada di kawasan Taman Jomblo, selain pedagang kaki lima yang menjual cinderamata atau aksesoris, pedagang kaki lima juga menjual makanan dan minuman umumnya dapat digolongkan produsen pedagang. Sedangkan pedagang kaki lima yang menjual pakaian, cenderamata atau aksesoris umumnya dapat digolongkan sebagai pedagang. Jenis usaha makanan dan minuman mempunyai pendapatan relatif lebih tinggi daripada jenis usaha lainnya. Hal ini karena produk makanan dan minuman merupakan kebutuhan yang sangat dibutuhkan manusia, meskipun produk mengalami kenaikan harga, makanan dan minuman masih banyak diminati dan dibutuhkan banyak orang. 
Menurut penulis, jenis usaha PKL yang baik untuk dikembangkan dengan memperhatikan prospek dan tingkat kontribusi terhadap pendapatan adalah jenis usaha makanan dan minuman.

Berdasarkan data yang diperoleh dari hasil penelitian di lapangan, jumlah PKL makanan dan minuman di trotoar sekitar Taman Jomblo Kota Baru Jambi pada januari tahun 2020 berjumlah kurang lebih 136 pedagang, di antaranya 119 pedagang kaki lima (PKL) pada malam hari dan 17 pedagang kaki lima (PKL) di siang hari. Hal ini menjadi perbedaan yang sangat kontras terhadap pendapatan yang di peroleh oleh pedangang kaki lima (PKL) yang berada dikawasan Taman Jomblo Kota Jambi terlebih jika pada hari libur jumlah pedagang kaki lima akan bertambah.

\section{Pengertian Pedagang Kaki Lima Menurut Para Ahli}

Menurut Evens dan Korff , "definisi pedagang kaki lima adalah bagian dan sektor informal kota yang yang mengebangkan aktivitas produksi barang dan jasa di luar kontrol pemerintah dan tidak terdaftar".

\section{Pengertian Packaging (Kemasan)}

Kotler dan Amstrong (2012) mendefinisikan "packaging involves designing and producing the container or wrapper for a product"yang artinya adalah proses kemasan melibatkan kegiatan mendesain dan memproduksi, fungsi utama dari kemasan sendiri yaitu untuk melindungi produk agar produk tetap terjaga kualitasnya.

\section{Pendapatan Menurut Ahli}

Menurut Theodurus M.Tuanakotta (2000) pendapatan (Revenue) dapat didefinisikan secara umum sebagai hasil dari suatu perusahaan. Pendapatan adalah darah kehidupan dari suatu perusahaan. Mengingat pentingnya sangat sulit mendefinisikan pendapatan sebagai unsur akuntansi pada dirinya sendiri. Pada dasarnya pendapatan adalah kenaikan laba. Seperti laba pendapatan adalah proses arus penciptaan barang atau jasa oleh suatu perusahaan selama suatu kurun waktu tertentu. Umumnya, pendapatan dinyatakan dalam satuan moneter (uang).

\section{Modal}

Modal merupakan faktor produksi yang mempunyai pengaruh kuat dalam mendapatkan produktivitas atau output, secara makro modal merupakan pendorong besar untuk meningkatkan investasi baik secara langsung pada proses produksi maupun dalam prasarana produksi, sehingga mampu mendorong kenaikan produktivitas dan output.

Modal menurut KBBI adalah uang yang digunakan sebagai pokok atau induk untuk melakukan kegiatan perdagangan. Baik harta benda berupa uang maupun barang, selama mampu dan bisa digunakan untuk menghasilkan sesuatu yang bisa menambah kekayaan.

\section{Waktu Dagang}

Dalam penelitian ini yang dimaksud dengan waktu dagang bagi pedagang kaki lima adalah lamanya waktu yang digunakan untuk menjalankan usaha. Di mulai sejak usaha tersebut buka sampai usaha jualannya tutup di setiap harinya. Semakin lama jam kerja yang digunakan pedagang untuk menjalankan usahanya, berdasarkan jumlah barang yang ditawarkan, maka semakin besar pula peluang untuk memperoleh pendapatannya.

Usaha pemerintah kota dalam mengupayakan keberhasilan pembangunan baik fasilitas umum maupun ekonomi masyarakatnya haruslah dengan kebijaksanaan yang matang. Selain itu, di samping jam kerja yang efektif dan fasilitas pendukung di sekitar wisata Taman Jomblo adalah keterampilan dan pengalaman usaha dari pedagang kaki lima itu sendiri, baik itu disiplin dalam bekerja ataupun inovasi-inovasi baru yang di tuangkan bagi mereka yang sudah lama berpengalaman.

\section{METODE}

Populasi

Populasi adalah keseluruhan data yang menjadi pusat perhatian seorang peneliti dalam ruang lingkup dan waktu yang telah ditentukan. Populasi berkaitan dengan data-data, jika seorang manusia memberikan suatu data, maka ukuran atau banyaknya populasi akan sama banyaknya manusia. Jadi, populasi merupakan sekelompok orang, kejadian atau hal-hal yang menarik untuk diteliti yang dibatasi oleh peneliti itu sendiri.

Populasi dari penelitian ini adalah semua pedagang kaki lima yang berjenis kelamin perempuan di Taman Jomblo Kotabaru Jambi yang berjumlah 136 pedagang, yang mana jumlah pedagang kaki lima yang berjenis kelamin laki-laki berjumlah 84 pedangang dan yang perempuan berjumlah 53 pedagang.

\section{Sampel}

Populasi yang terdapat dalam penelitian ini adalah pedagang kaki lima di Taman Jomblo Kota Jambi yang dibatasi pada sampel pedagang makanan, pedagang minuman, pedagang mainan anak, dan pedagang pakaian menurut hasil yang dikumpulkan oleh penulis berjumlah 136 pedagang yang menyebar di sekitar Taman Jomblo Kota Jambi. Untuk menetukan ukuran sampel maka digunakan rumus Slovin sebagai berikut:

$$
n=\frac{N}{1+N \cdot e^{2}}
$$

Keterangan:

$\mathrm{n} \quad=$ Jumlah sampel

$\mathrm{N}=$ Jumlah populasi pedagang kaki lima diTaman

Jomblo Kota Jambi

$\mathrm{e}=$ batas toleransi kesalahan (tingkat signifikansi 
Berdasarkan jumlah populasi dari Jumlah Pedagang Kaki Lima yang ada di Wisata Taman Jomblo tersebut dengan tingkat toleransi kesalahan sebesar 10 $\%$, maka dapat ditentukan sampel sebagai berikut: Populasi $=136$ pedagang kaki lima Batas kesalahan = $10 \%$. Berdasarkan hasil dari rumus slovin, maka jumlah sampel yang ditentukan sebanyak 58 sampel.

\section{Metode Analisis Data}

\section{Analisis Deskriftif}

Untuk menjawab tujuan dari rumusan masalah yang pertama yakni mengetahui pengaruh waktu dagang, modal, dan lokasi terhadap pendapatan pedagang kaki lima di Taman Jomblo Kota Jambi digunakan analisis deskriftif. Dalam metode ini dilakukan menggunakan metode wawancara terstruktur, studi pustaka dan kuisioner.

2. Analisis Regresi Berganda

Untuk mengetahui permasalah yang kedua digunakan model analisis regresi berganda dengan rumus:

\section{$\operatorname{LnY}=\operatorname{Ln} \beta_{0}+\beta_{1} \operatorname{Ln} X_{1}+\beta_{2} \operatorname{Ln} X_{2}+\beta_{3} \operatorname{LnX} X_{3}+e$}

Dimana :

$\mathrm{Y}=$ Pendapatan (Rupiah)

$\beta_{0}=$ Konstanta

$\beta_{1} \beta_{2} \beta_{3}=$ Koefisien Regresi

$\mathrm{X}_{1}=$ packaging

$\mathrm{X}_{2}=$ modal (rupiah)

$\mathrm{X}_{3}=$ waktu dagang $(\mathrm{jam})$

$\mathrm{e}=$ Eror term

\section{Uji Hipotesis}

Uji hipotesis digunakan untuk membuktikan hipotesis diterima atau ditolak, yang terdiri dari uji simultan (uji F-hitung), uji parsial (uji t).

\section{Uji Simultan (F)}

Untuk melakukan pengujian hipotesis yang mampu menerangkan hubungan seluruh variabel maka digunakan uji simultan (uji F). Uji F digunakan untuk mengetahui apakah semua variabel bebas secara bersama-sama (simultan) dapat berpengaruh terhadap variabel terikat. Uji $\mathrm{F}$ digunakan untuk menghitung besarnya perubahan nilai variabel terikat yang dapat dijelaskan oleh perubahan nilai semua variabel bebas. Pengujian ini dilakukan dengan melihat nilai signifikansi pada $\mathrm{F}_{\text {hitung }}$ jika nilai sig. $\leq 0,05$ maka Ho ditolak, artinya variabel bebas berpengaruh signiifikan terhadap variabel terikat, sedangkan jika nilai sig. > 0,05 maka Ho diterima, artinya variabel bebas tidak berpengaruh signifikan terhadap variabel terikat (Sugiyono, 2010).

\section{Uji Parsial (T)}

Uji t pada dasarnya menunjukkan seberapa jauh pengaruh satu variabel independen secara individual dalam menerangkan variasi variabel dependen (Ghozali, 2006). uji $\mathrm{T}$ digunakan untuk mengetahui besarnya signifikansi pengaruh variabel bebas terhadap variabel terikat secara individual (parsial), dengan menganggap variabel lain bersifat konstanta. Jika nilai sig. $\leq 0,05$ maka Ho ditolak, artinya variabel bebas berpengaruh signifikan terhadap variabel terikat, sedangkan jika nilai sig. > 0,05 maka Ho diterima, artinya variabel bebas tidak berpengaruh signifikan terhadap variabel terikat.

\section{HASIL DAN PEMBAHASAN}

Kegiatan sektor informal menurut kamus besar bahasa Indonesia merupakan salah satu kegiatan sektor ekonomi yang terdiri atas unit usaha berskala kecil, yang memproduksi dan mendistribusikan barang dan jasa dengan tujuan menciptakan kesempatan untuk mendapatkan pendapatan bagi para pelakunya.

Pada bab ini menjelaskan hasil penelitian dari data - data statistik pengolahan data yang telah dikumpulkan melallui kuesioner dengan responden sebanyak 58 pedagang kaki lima yang menjual makanan, minuman, aksesoris atau baju, dan campuran yang berada di wisata Taman Jomblo Kecamatan KotaBaru Jambi. Hasil penelitian yang peneliti paparkan dalam bab ini adalah untuk menjawab rumusan masalah dan pengujian hipotesis yang telah di kemukakan pada bab sebelumnya.

\section{Karakteristik Pendapatan Pedagang Kaki Lima (PKL) Di Wisata Taman Jomblo Kotabaru Jambi Tingkat Pendapatan Pedagang Kaki Lima Di Wisata Taman Jomblo Kotabaru Jambi}

Tujuan pokok dijalankannya suatu usaha perdagangan adalah untuk memperoleh pendapatan, dimana pendapatan tersebut dapat digunakan untuk memenuhi kebutuhan hidup dan kelangsungan usaha dagangnya. Dalam penelitian ini yang dimaksud pendapatan adalah jumlah uang yang diterima oleh pedagang dari aktivitas usaha yang dilakukannya dalam periode tertentu.

Mengenai pendapatan pedagang kaki lima di wisata Taman Jomblo Kotabaru Jambi di peroleh gambaran sebagai berikut:

Tabel 1. Deskripsi Besar Pendapatan PKL di Wisata Taman Jomblo Kotabaru Jambi

\begin{tabular}{|c|c|l|c|c|}
\hline No & Indikator & \multicolumn{1}{|c|}{ Pendapatan Pedagang } & Jumlah Responden & Presentase ( \%) \\
\hline 1. & Pendapatan perhari & $\mathrm{Rp}<100.000$ & 0 & $0 \%$ \\
& & $\mathrm{Rp} 100.000-500.000$ & 7 & $12,1 \%$ \\
& & $\mathrm{Rp} 500.000-1.000 .000$ & 50 & $82,6 \%$ \\
& & $\mathrm{Rp}>1.500 .000$ & 1 & $1,7 \%$ \\
\hline \multicolumn{2}{|c|}{ Jumlah } & $\mathbf{5 8}$ & $\mathbf{1 0 0 \%}$ \\
\hline
\end{tabular}


Dari Tabel di atas terlihat bahwa pendapatan perhari yang diterima pedagang kaki lima (PKL) terbanyak berkisar Rp 500.000 - Rp 1.000 .000 per hari dengan persentase sebesar 82,6 \%. Sedangkan pendapatan perhari pedagang kaki lima (PKL) terbesar di terima pada kisaran Rp lebih dari 1.500 .000 perhari dengan persentase $1,7 \%$.
Kemasan Pada Produk Usaha Pedagang Kaki Lima Di Wisata Taman Jomblo Kotabaru Jambi

Kemasan pada penelitian ini diukur dengan indikator bahan atau material kemasan yang terdapat pada produk. Menegenai kemasan pada produk usaha pedagang kaki lima di wisata Taman Jomblo Kotabaru Jambi di peroleh gambaran sebagai berikut:

Tabel 2. Deskripsi Kemasan Produk PKLdi Wisata Taman Jomblo Kotabaru Jambi

\begin{tabular}{|c|c|c|c|c|}
\hline No & Indikator & Material Kemasan & Jumlah Responden & Presentase ( \%) \\
\hline 1. & Kemasan produk & 1. $\quad$ Plastik & 27 & $46,6 \%$ \\
\hline & & 2. Kertas & 3 & $5,2 \%$ \\
\hline & & 3. Kaleng/Botol Kaca & 5 & $8,6 \%$ \\
\hline & & 4. Styrofoam & 23 & $39,7 \%$ \\
\hline \multicolumn{3}{|c|}{ Jumlah } & 58 & $100 \%$ \\
\hline
\end{tabular}

Sumber: Data Primer Diolah

Dari hasil Tabel diatas tanggapan responden akan variabel kemasan menunjukkan nilai tertingi adalah pada kemasan plastik sebesar 46,6\% dan yang paling rendah yaitu kemasan dengan kertas yakni sebesar 5.2 \%.. Hal ini menjelaskan bahwa responden memiliki kecenderungan yang tinggi terhadap material dan tingkat kepraktisan pada kemasan yang dipakai pada saat kegiatan berlangsung.

\section{Modal Pada Produk Usaha Pedagang Kaki Lima Di Wisata Taman Jomblo Kotabaru Jambi}

Dalam sebuah usaha, baik itu dalam usaha kecil seperti Pedagang Kaki Lima (PKL) juga membutuhkan modal usaha. Besar kecilnya suatu modal yang dimilikki tentu berpengaruh pada kelangsungan suatu usaha. Mengenai modal usaha, dalam penelitian ini peneliti mengukurnya melalui kuesioner yang diberikan kepada pedagang kaki lima dengan sejumlah pertanyaan. Adapun dari 58 reponden yang berhasil di kumpulkan, di peroleh gambaran sebagai berikut:

Tabel 3. Deskripsi Besar Modal PKL di Wisata Taman Jomblo Kotabaru Jambi

\begin{tabular}{|l|l|ll|c|c|}
\hline No & \multicolumn{1}{|c|}{ Indikator } & \multicolumn{1}{c|}{ Modal Usaha } & Jumlah Responden & Presentase ( \%) \\
\hline 1. & Modal & 1. & $\mathrm{Rp}<500.000$ & 4 & $6,9 \%$ \\
& Operasional & 2. & $\mathrm{Rp} 500.000-1.000 .000$ & 23 & $39,7 \%$ \\
& & 3. & $\mathrm{Rp} 1.000 .000-1.500 .000$ & 31 & $53,4 \%$ \\
& & 4. & $\mathrm{Rp}>1.500 .000$ & 0 & $0 \%$ \\
\hline \multicolumn{2}{|c|}{ Jumlah } & $\mathbf{5 8}$ & $\mathbf{1 0 0 \%}$ \\
\hline
\end{tabular}

Sumber: Data Primer Diolah

Dari Tabel 3 diatas terlihat bahwa modal operasional di keluarkan pedagang kaki lima paling sedikit yakni kurang lima ratus ribu rupiah dengan jumlah persentase responden $6,9 \%$, sedangkan modal operasional terbesar yang banyak digunakan dengan jumlah satu juta rupiah sampai dengan satu juta lima ratus ribu rupiah rupiah adalah sebesar 53,4 \% .

\begin{abstract}
Waktu Dagang Pedagang Kaki Lima Di Wisata Taman Jomblo Kota Baru Jambi

Waktu dagang adalah lamanya waktu yang digunakan untuk menjalankan usaha yang di pengaruhi oleh jumlah hasil produksi, dimulai sejak buka sampai dengan usaha berdagang itu tutup. Waktu kerja diukur dari lama kerja dalam hitungan jam. Adapun hasil penelitian tentang waktu dagang pedagang kaki lima dijelaskan dalam Tabel berikut:
\end{abstract}

Tabel 4. Deskripsi Waktu Dagang PKL di Wisata Taman Jomblo Kotabaru Jambi

\begin{tabular}{|c|c|c|c|c|}
\hline No & Indikator & $\begin{array}{c}\text { Waktu Dagang } \\
\text { Jam (WIB) }\end{array}$ & $\begin{array}{c}\text { Jumlah } \\
\text { Responden }\end{array}$ & $\begin{array}{c}\text { Presentase } \\
(\%)\end{array}$ \\
\hline 1. & $\begin{array}{l}\text { Waktu Dagang Yang Digunakan } \\
\text { Untuk berjualan }\end{array}$ & $\begin{array}{l}06.00-12.00 \\
12.00-18.00 \\
18.00-24.00 \\
24.00-06.00 \\
\end{array}$ & $\begin{array}{c}6 \\
4 \\
45 \\
3 \\
\end{array}$ & $\begin{array}{c}10,3 \% \\
6,9 \% \\
77,6 \% \\
5,2 \% \\
\end{array}$ \\
\hline \multicolumn{3}{|c|}{ Jumlah } & 58 & $100 \%$ \\
\hline
\end{tabular}


Berdasarkan Tabel diatas menunjukkan bahwa persentase waktu dagang yang terbesar digunakan oleh Pedagang Kaki Lima (PKL) di Wisata Taman Jomblo Kotabaru Jambi untuk menjual dagangannya kepada konsumen adalah $77,6 \%$ yakni pada pukul $18.00-$ 24.00. Sedangkan persentase waktu dagang yang terkecil digunakan oleh pedagang kaki lima adalah 5,2\% dengan jumlah responden 3 yakni pada pukul $24.00-$ 06.00 .

\section{Analisa Regresi}

Hasil analisis regresi linier berganda untuk mengetahui pengaruh kemasan $\left(X_{1}\right)$, modal $\left(X_{2}\right)$, dan waktu dagang $\left(\mathrm{X}_{3}\right)$ terhadap pendapatan pedagang kaki lima ( Y ) menggunakan program SPSS versi 22. Dimana hasil analisis statistik yang didapatkan di kemukakan pada Tabel 4.5 berikuti ini.

Tabel 5. Koefisien Regresi Linier Berganda Kemasan, Modal Usaha Dan Waktu Dagang Terhadap Pendapatan PKL Di Wisata Taman Jomblo KotaBaru Jambi

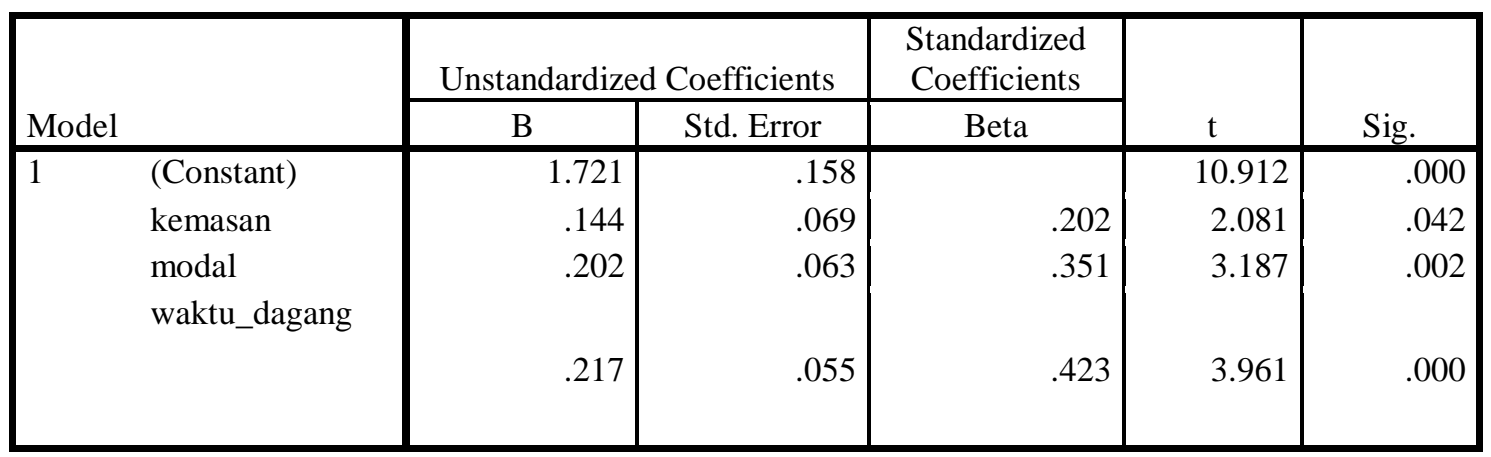

a. Dependent Variable: pendapatan

Dari Tabel diatas dapat di rumuskan secara matematika pengaruh variabel X1, X2, dan X3 terhadap Y sebagai berikut:

$\mathrm{Y}=1,721+0,144 \mathrm{X} 1+0,202 \mathrm{X} 2+0,217 \mathrm{X} 3+\mathrm{e}$

Dari persamaan regresi di atas didapatkan, Konstanta ( B0) 1,721

$\beta 1=0,144$

$\beta 2=0,202$

$\beta 3=0,217$

Nilai constanta yang didapatkan sebesar 1,721 bermakna bahwa kemasan, modal usaha, dan waktu dagang dianggap ada ( positif ) dan memiliki pertambahan. Selanjutnya untuk variabel Kemasan 0,144 bernilai positif, hal hasil ini menunjukan setiap kenaikan $1 \%$ untuk kemasan produk maka akan meningkatkan pendapatan Pedagang Kaki Lima (PKL) Wisata Taman Jomblo Kotabaru Jambi sebesar 14,4 \%.

Pada variabel Modal usaha bernilai 0,202 (positif) artinya setiap penambahan modal usaha yang dikeluarkan PKL di lokasi tersebut maka akan meningkatkan jumlah pendapatan Pedagang Kaki Lima (PKL) sebesar 20,2\% atau memiliki makna setiap 1\% penambahan modal yang di lakukan oleh PKL mempengaruhi kenaikan pada pendapatan pedagang kaki lima.

Selanjutnya untuk variabel Waktu Dagang bernilai 0,217 (positif). Hal ini memberikan makna bahwa setiap penambahan 1 jam waktu dagang, maka akan meningkatkan jumlah pendapatan Pedagang Kaki Lima (PKL) Wisata Taman Jomblo Kotabaru Jambi sebesar $21,7 \%$.

\section{Pengujian Hipotesis}

Tabel 6. Hasil Regresi Uji T

\begin{tabular}{|c|c|c|c|c|c|c|}
\hline \multirow{2}{*}{\multicolumn{2}{|c|}{ Model }} & \multicolumn{2}{|c|}{ Unstandardized Coefficients } & \multirow{2}{*}{$\begin{array}{c}\text { Standardized } \\
\text { Coefficients }\end{array}$} & \multirow[b]{2}{*}{$\mathrm{T}$} & \multirow[b]{2}{*}{ Sig. } \\
\hline & & $\mathrm{B}$ & Std. Error & & & \\
\hline \multirow[t]{4}{*}{1} & (Constant) & 1.721 & .158 & & 10.912 & .000 \\
\hline & Kemasan & .144 & .069 & .202 & 2.081 & .042 \\
\hline & Modal & .202 & .063 & .351 & 3.187 & .002 \\
\hline & waktu_dagang & .217 & .055 & .423 & 3.961 & .000 \\
\hline
\end{tabular}

a. Dependent Variable: pendapatan

Pada Tabel diatas uji $\mathrm{t}$ dipergunakan untuk menjawab hipotesis yang diajukan pada penelitian ini .
Dalam penelitian ini hipotesis pertama adalah apakah terdapat hubungan yang positif dan signifikan variabel 
bebaas terhadap variabel terikat secara parsial. Dari hasil hitung statistk di peroleh untuk variabel kemasan (X1), diperoleh $\mathrm{t}$ hitung $=2,081>\mathrm{t}$ Tabel 1,673 atau nilai signifikan sebesar 0,042 pada taraf kepercayaan $95 \%$ atau $\alpha 0,05$. Hal ini menunjukan adanya pengaruh positif dan signifikan (nyata) antara kemasan ( $\mathrm{X}_{1}$ ) terhadap pendapatan pedagang kaki lima (Y). dengan demikian berarti Ho ditolak atau Ha diterima.

Hasil perhitungan statistik untuk variabel modal $\left(\mathrm{X}_{2}\right)$, di peroleh $\mathrm{t}_{\text {hitung }}=3,187>\mathrm{t}$ Tabel $=1,673$ atau signifikan sebesar 0,002. Dengan demikian maka Ho ditolak dan $\mathrm{Ha}$ diterima, sehingga hipotesis yang menyatakan ada pengaruh dan singnifikan antara modal usaha $\left(\mathrm{X}_{2}\right)$ terhadap pendapatan pedagang kaki lima ( $\mathrm{Y}$ ) dapat diterima.

Sedangkan untuk variabel waktu dagang $\left(\mathrm{X}_{3}\right)$, diperoleh nilai $\mathrm{t}_{\text {hitung }}=3,961>\mathrm{t}_{\text {Tabel }}=1,673$ dengan nilai signifikan sebesar 0,000 pada taraf kepercayaan $5 \%$. Dengan demikian maka Ho ditolak dan Ha di tterima, sehinngga hipotesis yang menyatakan ada pengaruh positif dan signifikan antara waktu dagang $\left(\mathrm{X}_{3}\right)$ terhadap pendapatan pedagang kaki lima (Y).

Dari ketiga variabel yang mempengaruhi pendapatan pedagang kaki lima, berdasarkan hasil regresi menunjukan variabel kemasan dan variabel modal berpengauh positif dan signifikan terhadap pendapatan pedagang kaki lima di wisata Taman Jomblo Kotabaru Jambi. Namun dari hasil regresi linier berganda pada variabel waktu dagang memiliki pengaruh (positif) yang besar dan signifikan dengan kata lain setiap penambahan 1 jam waktu dagang yang di lakukan, sangat berpengaruh terhadap tingkat pendapatan pedagang kaki lima diwisata Taman Jomblo Kotabaru Jambi.

Untuk mengetahui pengaruh secara simultan ( bersama - sama ) variabel bebas dalam mempengaruhi variabel terikat maka uji signifikan dilakukan uji $\mathrm{F}_{\text {hitung. }}$

Tabel 7. Hasil Uji F ANOVA ${ }^{a}$

\begin{tabular}{|ll|r|r|r|r|r|}
\hline Model & & Sum of Squares & Df & Mean Square & F & Sig. \\
\hline 1 & Regression & 3.910 & 3 & 1.303 & 20.283 & $.000^{\mathrm{b}}$ \\
& Residual & 3.470 & 54 & .064 & & \\
& Total & 7.379 & 57 & & & \\
\hline
\end{tabular}

a. Dependent Variable: pendapatan

b. Predictors: (Constant), waktu_dagang, kemasan, modal

Tabel 8. Model Summary

\begin{tabular}{|l|r|r|r|r|}
\hline Model & R & R Square & \multicolumn{1}{c|}{$\begin{array}{c}\text { Adjusted R } \\
\text { Square }\end{array}$} & $\begin{array}{c}\text { Std. Error of the } \\
\text { Estimate }\end{array}$ \\
\hline 1 & $.728^{\mathrm{a}}$ & .530 & .504 & .253 \\
\hline
\end{tabular}

a. Predictors: (Constant), waktu_dagang, kemasan, modal

Dari hasil perhitungan maka diperoleh nilai $\mathrm{F}$ sebesar 20.283. Sedangkan $\mathrm{F}_{\text {Tabel }}$ pada taraf kepercayaan $5 \%(\alpha 0,05)\left(\mathrm{df}_{1}=(\mathrm{k}-1) 3-1=2\right.$ dan $\mathrm{df}_{2}=\mathrm{n}-\mathrm{k}-1=58-3-$ $1=54)$ diketahui nilai $F_{\text {Tabel }} 3$,17. Artinya $F_{\text {hitung }}=$ $20.283>\mathrm{F}_{\text {Tabel }}=3,17$ atau nilai ssignifikasi $0,000<$ 0,05 . Dengan demikian Ho ditolak dan Ha diterima atau ada pengaruh positif kemasan $\left(\mathrm{X}_{1}\right)$, modal $\left(\mathrm{X}_{2}\right)$, dan waktu dagang $\left(\mathrm{X}_{3}\right)$ terhadap pendapatan pedagang kaki lima $(\mathrm{Y})$ dan signifikan di terima.

Berdasarkan analisis dari tabel di atas menunjukan besarnya korelasi $\left(\mathrm{R}^{2}\right)$ Modal, Lama Usaha, Dan Waktu Dagang secara bersama-sama dengan Pendapatan Pedagang Kaki Lima yaitu sebesar 0,728 atau 72,8 \%. Nilai tersebut menunjukan hubungan korelasi yang tinggi antara variabel $\mathrm{X}_{1}, \mathrm{X}_{2}, \mathrm{X}_{3}$, dan dengan $\mathrm{Y}$. Selanjutnya $R$ Square ( koefisien determinasi / $R^{2}$ ) sebesar 0,530 memberi pengertian bahwa 53,0 \% Pendapatan Pedagang Kaki Lima (PKL) Wisata Taman Jomblo Kotabaru Jambi ditentukan oleh Kemasan, Modal, Dan Waktu Dagang, sedangkan sisanya merupakan kontribusi faktor yang tidak di teliti yaitu sebesar $47.0 \%$.

\section{SIMPULAN}

Berdasarkan analisis yang telah dilakukan, dapat diperoleh kesimpulan sebagai berikut :

1. Kemasan berpengaruh positif dan signifikan terhadap pendapatan Pendapatan Pedagang Kaki Lima di Wisata Taman Jomblo Kotabaru Jambi. Modal berpengaruh positif dan signifikan terhadap pendapatan Pendapatan Pedagang Kaki Lima di Wisata Taman Jomblo Kotabaru Jambi. Waktu Dagang berpengaruh positif dan signifikan terhadap pendapatan Pedagang Kaki Lima di Wisata Taman Jomblo Kotabaru Jambi.

2. Secara bersama-sama Modal, Lama Usaha, dan Waktu Dagang berkorelasi dengan pendapatan Pedagang Kaki Lima yaitu sebesar $72,8 \%$, dan memepengaruhi pendapatan Pedagang Kaki Lima (PKL) Wisata Taman Jomblo Kotabaru Jambi sebesar $53,0 \%$. Hal ini disebabkan variabel yang diteliti oleh penulis pada saat pandemic Covid-19, sehingga setiap penambahan modal $1 \%$ dan penambahan waktu 1 jam yang di lakukan pedagang sangat 
Ratih Rosita, Irmanelly dan Ermaini, Analisis Faktor-Faktor Yang Mempengaruhi Pendapatan Pedagang Kaki Lima (Studi Kasus Wisata Taman Jomblo Kotabaru Jambi Pasca Pandemi Covid-19)

berpengaruh terhadap tingkat pendapatan Pedagang Kaki Lima di wisata Taman Jomblo Jambi.

\section{DAFTAR PUSTAKA}

Allam Ammar, Muhammad,. Rahajuni, Dijan, dkk (2019), Faktor Yang Mempengaruhi Pendapatan Pedagang Kaki Lima (Pkl) Di Pasar Sunday Morning (Sunmor). Purwokerto. Faculty of Economics and Business, Jenderal Soedirman University

Aris, Dewa Made. (2015). Analisis Faktor-Faktor yang Mempengaruhi Pendapatan Pedagang Pasar Seni Sukawati di Kabupaten Gianyar. Tesis Ekonomi. Universitas Udayana, Bali.

Atun Isni, Nur. (2016), Pengaruh Modal, Lokasi, Dan Jenis Dagangan Terhadap Pendapatan Pedagang Pasar Prambanan Kabupaten Sleman.

Chintya Ajeng, Wery, dkk (2013), Analisis Pendapatan Pedagang Kaki Lima Di Pasar Jimbaran Kelurahan Jimbaran.

Fatmawati. (2014), Analisis Faktor - Faktor Yang Mempengaruhi Pendapatan Pedang Kaki Lima Di Pasar Raya Padang. Padang

Isrohah, Rohmatul. (2015). Analisis Pengaruh Modal Kerja dan Jam Kerja Terhadap Bersih Pedagang Kaki Lima di Kelurahan Ngaliyan Semarang (Studi Kasus Pedagang Kaki Lima Di Kelurahan Ngaliyan Semarang. Skripsi Ekonomi dan Bisnis Islam. Universitas Islam Negeri Walisongo, Semarang.

Kartiningsih. (2016). Pengaruh Modal, Lama Usaha, Jam Kerja dan Tingkat Pendidikan Terhadap Peningkatan Pendapatan Pedagang Kaki Lima di Alun-Alun Raden Bagus Assra Kironggo Kabupaten Bondowoso. Skripsi Ekonomi. Universitas Jember, Jember.

Okti Nurani, Dwi. (2010), Analisis Faktor-Faktor Yang Berpengaruh Terhadap Pendapatan Pedagang Kaki Lima Makan Dan Minuman Di Jalan Malioboro Yogyakarta. Yogyakarta

Priyandika Nurseta, Akhbar. (2015), Analisis Pengaruh Jarak, Lama Usaha, Modal, Dan Jam Kerja Terhadap Pendapatan Pedagang Kaki Limakonveksi.

Putra Adi Candra Gede, Komang, (2018) Analisis Faktor-Faktor Yang Mempengaruhi Pendapatan Pedagang Di Pasar Badung Kota Denpasar : Studi Sebelum Dan Sesudah Di Relokasi. Bali

Umar, Tirtaraharadja dan LA Sulo. 2005. Pengantar pendidikan(edisi revisi) PT Rineka Cipta. Jakarta.

Wahyono, Budi. (2017), Analisis Faktor-Faktor Yang Mempengaruhi Pendapatan Pedagang Di Pasar Bantul. Bantul

Wiwin, Agustina. (2017), Analisis Faktor Yang Mempengaruhi Pendapatan Pedagang Kaki Lima Di Seberang Ulu II Paju. 